\title{
Structural Reliability and Damage Tolerance of Ceramic Composites for High-Temperature Applications Semi-Annual Progress Report for the Period Ending September 30, 1987
}

E. R. Fuller, Jr., T. W. Coyle, and R. F. Krause, Jr.

U.S. DEPARTMENT OF COMMERCE

National Bureau of Standards

Ceramics Division

Gaithersburg, MD 20899

October 1987

Issued February 1988

Prepared for

U.S. Department of Energy Fossil Energy

Advanced Research \& Technology Development Fossil Energy Material Program Oak Ridge National Laboratory Oak Ridge, TN 



\section{STRUCTURAL RELIABILITY AND DAMAGE TOLERANCE OF CERAMIC COMPOSITES FOR HIGH-TEMPERATURE APPLICATIONS SEMI-ANNUAL PROGRESS REPORT FOR THE PERIOD ENDING SEPTEMBER 30, 1987}

E. R. Fuller, Jr., T. W. Coyle, and R. F. Krause, Jr.

\section{U.S. DEPARTMENT OF COMMERCE \\ National Bureau of Standards \\ Ceramics Division \\ Gaithersburg, MD 20899}

October 1987

Issued February 1988

Prepared for

U.S. Department of Energy

Fossil Energy

Advanced Research \& Technology Development

Fossil Energy Material Program

Oak Ridge National Laboratory

Oak Ridge, TN

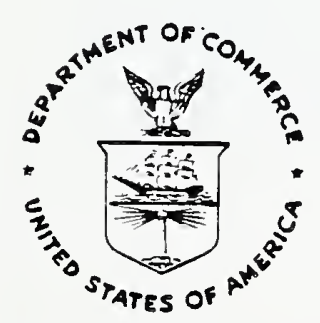

U.S. DEPARTMENT OF COMMERCE, C. William Verity, Secretary NATIONAL BUREAU OF STANDARDS, Ernest Ambler, Director 



\title{
STRUCTURAL RELIABILITY AND DAMAGE TOLER NCE OF CERAMIC COMPOSITES FOR HIGH-TEMPERATURE APPLICATIONS
}

Semi-Annual Progress Repcrt for the Period Ending September 30, 1987

\author{
Prepared for US Department of Energy, Fossil Energy \\ Advanced Research \& Technology Development \\ Fossil Energy Material Program \\ Oak Ridge National Laboratory \\ Oak Ridge, TN
}

Interagency Agreement DE-AI05-800R206179

E. R. Fuller, Jr., T. W. Coyle, and R. F. Krause, Jr.

\author{
National Bureau of Standards \\ Institute for Materials Science and Engineering \\ Ceramics Division \\ Gaithersburg, MD 20899
}

\section{INTRODUCTION}

The achievement of higher efficiency heat engines and heat recovery systems requires the availability of high-temperature, high-performance structural materials. Structural ceramics, and more recently, ceramic matrix composites have received particular attention for these applications due to their high strength, and resistance to corrosion and thermal shock. Even with these positive attributes, improved reliability and extended lifetime under service conditions are necessary for structural ceramics to gain industrial acceptance. The problems with these materials are mechanical and chemical in nature and are enhanced by the fact that they are subjected to high temperatures, reactive environments and extreme thermal gradients.

With an objective of improved performance for heat engine/heat recovery applications, the NBS program on structural ceramics and ceramic composites addresses these problems through the determination of critical factors that influence mechanical and microstructural behavior. The activities of the program are grouped under two major subtasks, each designed to develop key data, associated test methods and companion predictive models. The status of the subtasks are detailed in the following sections. 

Subtask A: Interfacial and Microstructural Composite Properties

\section{Measurement of Fiber/Matrix Interfacial Forces}

Summary. An instrumented hardness machine was employed to characterize the mechanical behavior of the fiber/matrix interface in two types of composite specimens. Using the technique, described in past reports [1], several specimens of a Nicalon fiber-reinforced SiC composites provided by R.A. Lowden of Oak Ridge National Laboratory were examined. In addition, a variation of this technique was used to provide an independent analysis of the fiber/matrix interface of DCDC specimens, whose development and resting were reported in the previous semi-annual report [1]. Due to the much larger diameter of the AVCO SiC fibers used in the DCDC specimens, changes in the experimental technique and data analysis procedure were required from those previously developed for Nicalon fibers. Due to configurational changes in the displacement sensors of the instrumented hardness machine, modifications to the data analysis procedure were also necessary for specimens with Nicalon fibers.

Interfacial Forces in DCDC specimens. Discussions in previous progress reports on measurements of the fiber/matrix interfacial forces with the instrumented hardness machine dealt with testing of bulk

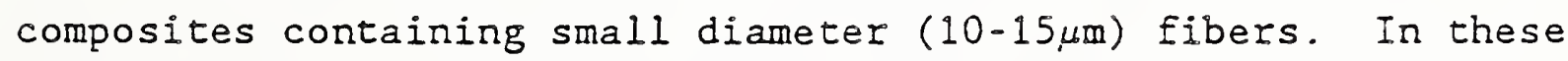
instances the specimen thickness was much larger than the distance along the fiber over which slippage occurred. The fibers used in the DCDC specimens are much larger in diameter $(140 \mu \mathrm{m})$. Since the force required to cause fiber slippage increases with the interfacial area between fiber and matrix, the specimen thickness must be reduced in order to limit the applied force required to an accessible experimental range. To simplify the analysis, the limiting condition of specimen thickness less than tine distance, over which slippage occurs, was adopted. In this case the shear strength of the interface $(\tau)$ is simply $\tau=F /(2 \pi R t)$, where $F$ is the 

axial force applied to the fiber, $R$ is the fiber radius and $t$ is the specimen thickness.

Samples were prepared from the broken halves of the DCDC specimens by diamond grinding them to a thickness of approximately $0.85 \mathrm{~mm}$ perpendicular to the fiber axis and then polishing. Load-displacement curves for two fibers are shown in Fig. 1. The tests typically show a maximum in the applied load followed by an abrupt drop to a plateau load which is nearly constant over several micrometers of displacement. The customary interpretation of this type of result is that the peak applied load corresponds to the applied shear stress required for debonding ( $\tau_{\mathrm{d} b}$ ) and the plateau load to the stress for frictional sliding $\left(\tau_{f}\right)$. Following this simple analysis the observed values of $\tau_{\mathrm{db}}$ range from 0.8 to $1.0 \mathrm{MPa}$ and those of $\tau_{f}$ from 0.4 to $0.7 \mathrm{MPa}$.

Nicalon fiber - SiC matrix composites. The materials examined were 2-D reinforced composites produced at Oak Ridge National Laboratory by a chemical vapor infiltration (CVI) process. The goal of the testing is to relate the strength of the interface to the various interfacial structures produced during the CVI fabrication process. The requisite flat, optically polished surface had been prepared on samples approximately $10 \mathrm{~mm}$ thick. Indentations were placed in several individual fibers for each specimen and the load and total indenter displacement recorded.

The total displacement measured during the test includes not only the fiber displacement but the displacement due to the penetration of the diamond indenter into the fiber and displacement due to the compliance of the sample support and stage as well. Recent changes in the configuration of the displacement sensor have made the latter contributions much larger and therefore the simple correction based on the fiber hardness (see [1]) is no longer adequate. A new procedure was developed to experimentally determine that part of the total displacement which was not due to the displacement of the fiber relative to the matrix. Indentations were placed in fibers laying parallel to the sample surface and therefore unable to move relative to the matrix. The load-displacement curve determined for these indentations can be subtracted from the curves recorded during indentation of fibers wose 

axis is perpendicular to the surface, thus correcting for both the compliance of the sample support and penetration of the diamond into the fiber. When this analysis is completed the results will be correlated with those of other characterization techniques to be performed at Oak Ridge National Laboratory.

\section{Characterization of Matrix Crack - Fiber Interactions}

Summary. The double cleavage drilled compression (DCDC) configuration has been used to study the effects of individual SiC fibers on crack propagation in glass specimens as previously reported [1]. Qualitative observations of the shape of the crack front and the fracture path in the vicinity of the fiber were made and some quantitative information regarding the closure forces exerted by bridging fiber was obtained. The fiber/matrix interfacial shear properties in representative specimens were recently evaluated by measuring the force required to push the fibers through thin sections of the glass matrix using the indentation technique discussed above. These results have been included in further efforts to quantify the effects of the fibers on. crack propagation in these specimens.

Analysis and discussion. An optical micrograph of the fracture surface of a DCDC specimen in the region about a fiber is shown in Fig. 2. The light and dark bands visible in the micrograph arise from the periodic undulations on the fracture surface by virtue of the differential interference contrast. These bands represent the shape and position of the crack front at periodic intervals of time [1]. Thus it can be seen that as the crack propagated through the specimen, it bowed around the fiber, then again formed a continuous front as it moved beyond the fiber, leaving the fiber bridging the crack.

The quantitative information obtained from the tests is based on stress intensity factor analyses of the DCDC specimen [2-6] which indicate that for a wide range of crack lengths the stress intensity factor $\left(K_{a p p}\right)$ due to the remotely applied compressive load $\left(\sigma_{a p p}\right)$ as a function of crack length (c) is well described the expression: 



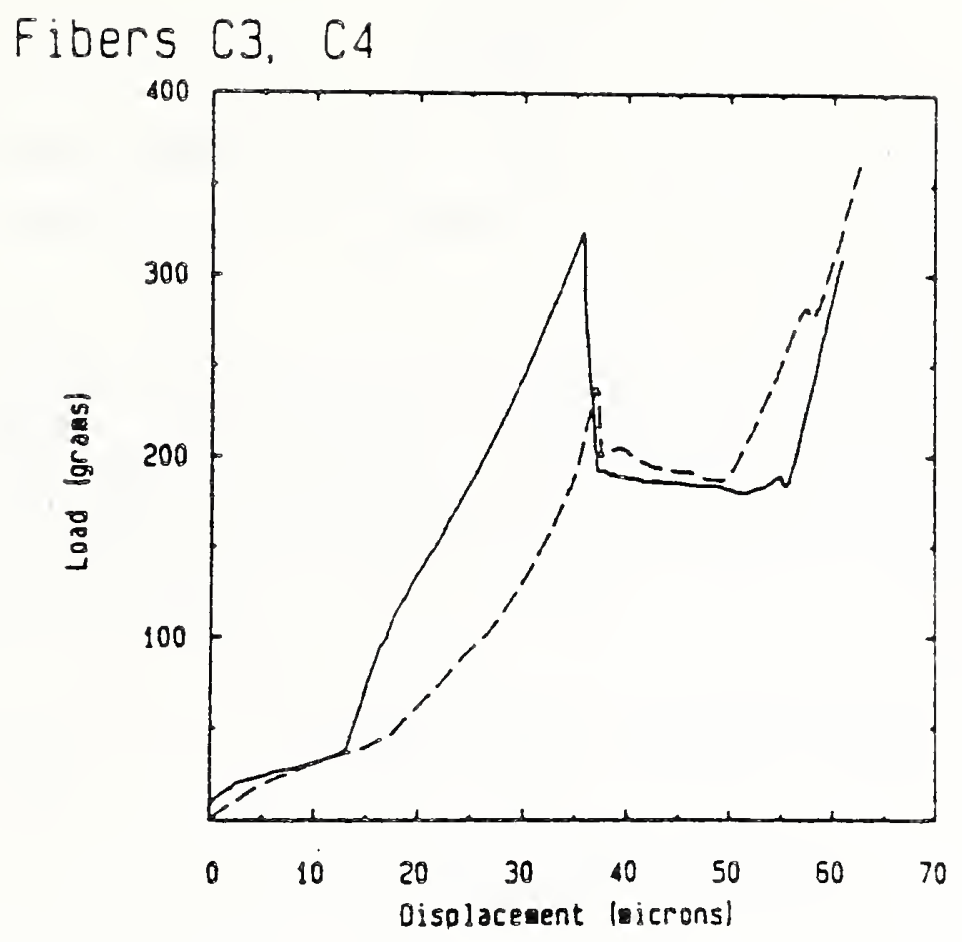

Figure 1. Curves showing axial load applied to the end of a fiber by the Vicker's indenter versus the displacement of the indenter. The abrupt load drop occurs as the fiber begins to slide through the glass matrix.

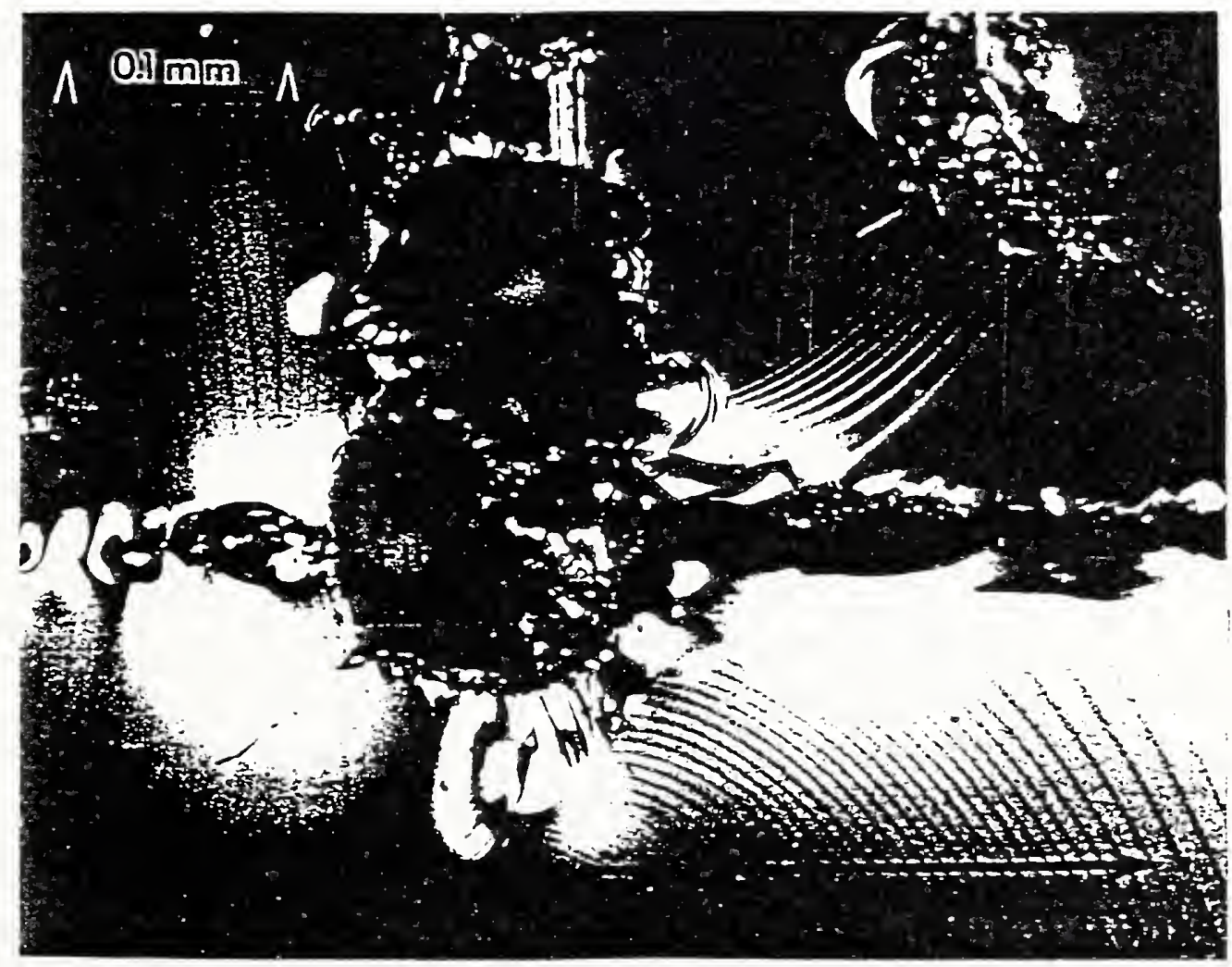

Figure 2. Optical micrograph of a region of the fracture surface centered about a reinforcing fiber. Differential interference contrast reveals the periodic surface undulations caused by the applied acoustic waves. 



$$
\frac{\sigma_{\operatorname{spp}} \sqrt{\mathrm{I}}}{\mathrm{K}_{\mathrm{qp}}}=\alpha \frac{\mathrm{c}}{\mathrm{x}}+\beta
$$

where $r$ is the radius of the center hole in the DCDC specimen. The constants $\alpha$ and $\beta$ can be evaluated empirically by testing specimens of known $\mathrm{K}_{\mathrm{IC}}$.

The stress intensity at the crack tip is assumed to be the critical stress intensity for the glass matxix $\left(K_{I C}\right)$ and is given by the sum of the remotely applied loading and the closure forces exerted by the bridging fiber $\left(K_{f \perp b}\right)$ :

$$
K_{t \perp p}=K_{I C}=K_{a p p}+K_{f 1 b}
$$

or

$$
K_{Q p p}=K_{I C}-K_{f i b}
$$

As seen in Fig. 2 the crack front is highly curved in the region near the fiber rendering detailed, rigorous analysis of these results extremely difficult. The following development does, however, provide some useful insight on factors affecting crack growth. Assume that the crack front develops a profile (Fig. 3) such that Eq. 2 is satisfied at all points along the front. The expression for $\mathrm{K}_{\mathrm{app}}$ depends only on the crack length, $c$, or on $x$, the distance beyond the fiber, and so cannot account for the curvature. Thus the curvature must arise from the form of the expression for $\mathrm{K}_{\mathrm{f} i \mathrm{~b}}$. The stress intensity factor along a straight crack front due to a point closure force, $F$, acting at a distance, $x$, behind the crack tip is given by [7]:

$$
K_{I}=-\frac{\sqrt{2} F}{(\pi x)^{3 / 2}}\left(\frac{x^{2}}{x^{2}+z^{2}}\right)
$$

where $z$ describes the position along the crack front. Substitution of Eq. 4 for $K_{f i b}$, with $F$ taken as the bridging force due to the fiber, and Eq. 1 for $\mathrm{K}_{\mathrm{app}}$ into Eq. 2 results in an expression which describes contours in the $x-z$ plane (the fracture surface) where $k_{i p}=k_{I}$ for given values of $\sigma_{\mathrm{app}}$ and $\mathrm{F}$ : 



$$
\mathrm{K}_{\text {tip }}=\frac{\sigma_{a p p} \sqrt{x}}{\alpha \frac{x}{r}+\alpha \frac{a}{x}+\beta}-\left(\frac{\sqrt{2} \sqrt{x} F}{\pi^{3 / 2}\left(x^{2}+z^{2}\right)}\right)
$$

where $a$ is the distance from the edge of the center hole to the fiber. It is difficult at this time to estimate the error involved in applying Eq. 4 to a curved crack front. Near the fiber, where the crack front curvature is large, Eq. 4 may significantly overestimate $\mathrm{K}_{\mathrm{f}+\mathrm{b}}$. The approximation of $F$ as a point force also becomes inadequate within a few fiber radii of the fiber location. Farther from the fiber, where the change in $x$ becomes small with respect to $z$ along the contours of constant $K_{t i p}$, the error should be modest. With an appropriate value of $F$, it should therefore be possible to rationalize the observed crack front profiles and to account for the range of interaction between the fiber and crack front.

The closure force is transferred from the fiber to the matrix through shear tractions acting across the fiber/matrix interface. Therefore the closure force exerted across the crack surfaces is controlled by the interfacial properties. To independently evaluate the response of the interface to applied shear stresses, the instrumented hardness machine was used to push fibers through thin sections fabricated from the broken halves of the DCDC specimens. Measured loaddisplacement curves for two fibers are shown in Fig. 1, as described above. An estimate of the magnitude of $F$ is obtained by multiplying $r$ by the interfacial area, i.e. $F=(\pi \mathrm{D} w / 2) \tau$.

Contours of $K_{t i p}=K_{I C}$ given by $E q .5$ with $F=0.7 \mathrm{~N}$ for several levels of applied stress are shown in Fig. 4, where the point force is located at the origin. The shape of the calculated, constant-kip contours have the same general shape as the crack front profiles shown in Fig. 2, suggesting that the character of the bridging interaction is fairly well described by Eq. 4. The spatial extent of the calculated interaction is also in fair agreement with that observed, indicating that the magnitude of the trial bridging force is of the correct order. However, in the region near the fiber, where the interactions are 



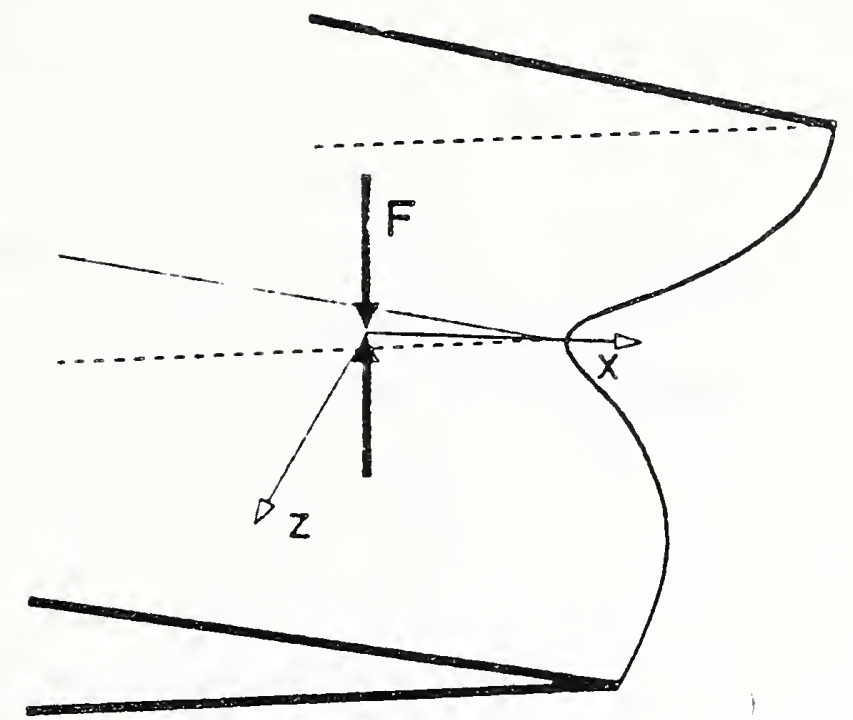

Figure 3. Schematic illustration of the bowed crack-front profile showing the $x-z$ coordinate system defined on the fracture surface with origin located at the position of the closure force, $F$.

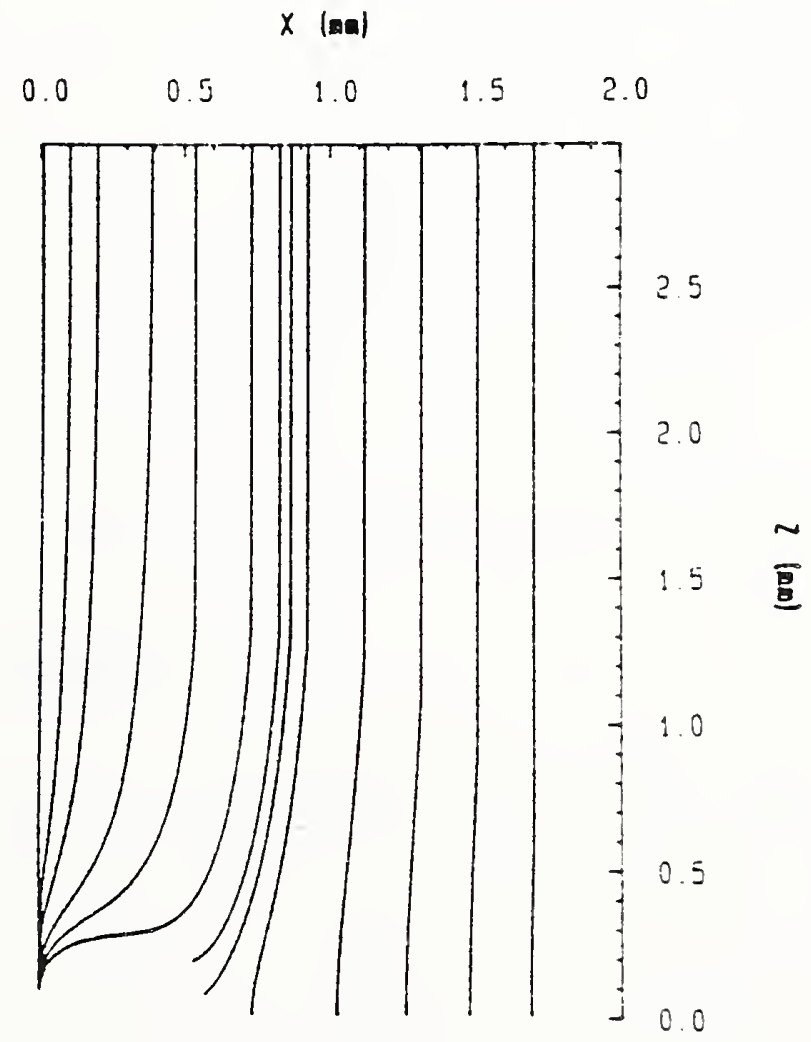

Figure 4. Contours of constant $k_{t i p}$ on the $x-z$ plane (the fracture surface) calculated using Eq. 5 for several values of $\sigma_{a p p}$ with $F=0.7 \mathrm{~N}$. Each contour, from left to right, corresponds to a larger $\sigma_{\text {app }}$. The point force (the fiber) is located in the lower left corner $(x=0, z=0)$. The area represented would extend from the center line of the DCDC specimen at $z=0$ to the specimen edge at $z=3.0$. 

strongest, the calculated contours do not describe the experimental observations very well. This may be due in part to the assumption of $F=$ constant used in this calculation.

From the results of the indentation experiments it is clear that the force exerted by the fiber varies with the relative displacement of the fiber and the matrix. The bridging force will therefore depend on the debonded length and the crack opening displacement (u). In principle the dependence on crack opening displacement could be introduced into Eq. 4 by taking $F=f(x)$. For example, when a simple frictional sliding resistance $\left(\tau_{f}=\right.$ constant) can be used to describe the resistance to shear of the interface, $F$ increases with $/ u$ (i.e., $F \propto u^{i / 2}$ ). Assuming $u \propto x^{1 / 2}$ would then give $F \propto x^{1 / 4}$. Substitution of such an expression for $F$ in Eq. 5 may yield better agreement with the observed crack front contours. However, several other factors could influence the shape of the contours in the region near the fiber as well. It is felt that the errors involved in applying expressions such as Eq. 4 to this situation preclude rigorous quantitative evaluation of the bridging force from the present results. Additional analysis, probably including finite element treatments of the system would be required. The qualitative understanding obtained from such experiments is valuable none-the-less, particularly in conjunction with independent evaluation of the fiber/matrix interfacial properties.

Subtask B: High-Temperature Damage Modes and Failure Mechanisms

\section{Eracture Toughness Behavior}

Summary. The fracture toughness behavior of a 25 wt percent silicon carbide whisker-reinforced alumina ceramic has been further characterized at room temperature to include a material with a porosity of 0.6 percent, thus supplementing previous measurements [1] at porosities of 4.9 and 11.5 percent. The composite materials were provided as billets through the courtesy of J. E. Rhodes of then ARCO Chemical Company [8]. The intrinsic, Flexural strength was determined, and noted to increase as a function of decreasing porosity. A varying flaw size, controlled by 

Vickers indentation loading between 2 and $200 \mathrm{~N}$, was placed on the previously polished ( $9 \mu \mathrm{m}$ finish), prospective tensile surfacts of fourpoint flexure specimens. The flexural strength was measured as a function of indentation load, and the results indicate that the fracture resistance of these materials increases as a function of crack extension. Furthermore, the fracture resistance is influenced by the bulk mass density. An increase in bulk mass density (a decrease in porosity) of the ceramic raises the level of fracture resistance, but has negligible effect on the susceptibility for the fracture resistance to increase with crack extension (i.e., rising $R$-curve behavior).

Intrinsic strength. The open circles which are arbitrarily plotted at $\log (P)=0$ in Fig. 5, correspond to the strength, $S_{0}$, for non-indented specimens. The other open circles in Fig. 5 show strengths of indented specimens, which did not rupture at the indentation flaw, also indicative of the intrinsic strength. Table 1 gives the mean $S_{0}$ indicated by all the open circles. The results reported earlier [1] for other porosities are included for comparison. Figure 6 shows $S_{0}$ as a function of the porosity, $p$. This function may be characterized by

$$
S_{0}=S_{m}(1-p)^{n}
$$

where $\mathrm{S}_{\mathrm{m}}$ and $\eta$ are constants. As the porosity approaches zero, which corresponds to a theoretical dense material, the intrinsic strength approaches its maximum value, $S_{m}$. A least squares fit, the solid line in Fig. 6, gives $S_{m}=694 \pm 8 \mathrm{MPa}$ and $\eta=4.12 \pm 0.14$, where the uncertainties are standard deviations.

Indented beam strength. Figure 5 also shows the bending strength, $S$, as a function of indentation load, $P$. This straight line function, which is the logarithm of

$$
S=S_{0}\left(P / P_{0}\right)^{-\beta}
$$

was fitted by a method of least squares to evaluate the constants: $\alpha=$ $S_{0} P_{0} \beta$ and $\beta$ at each porosity. Table 1 gives the values of $\beta$ and $P_{0}$ thus 



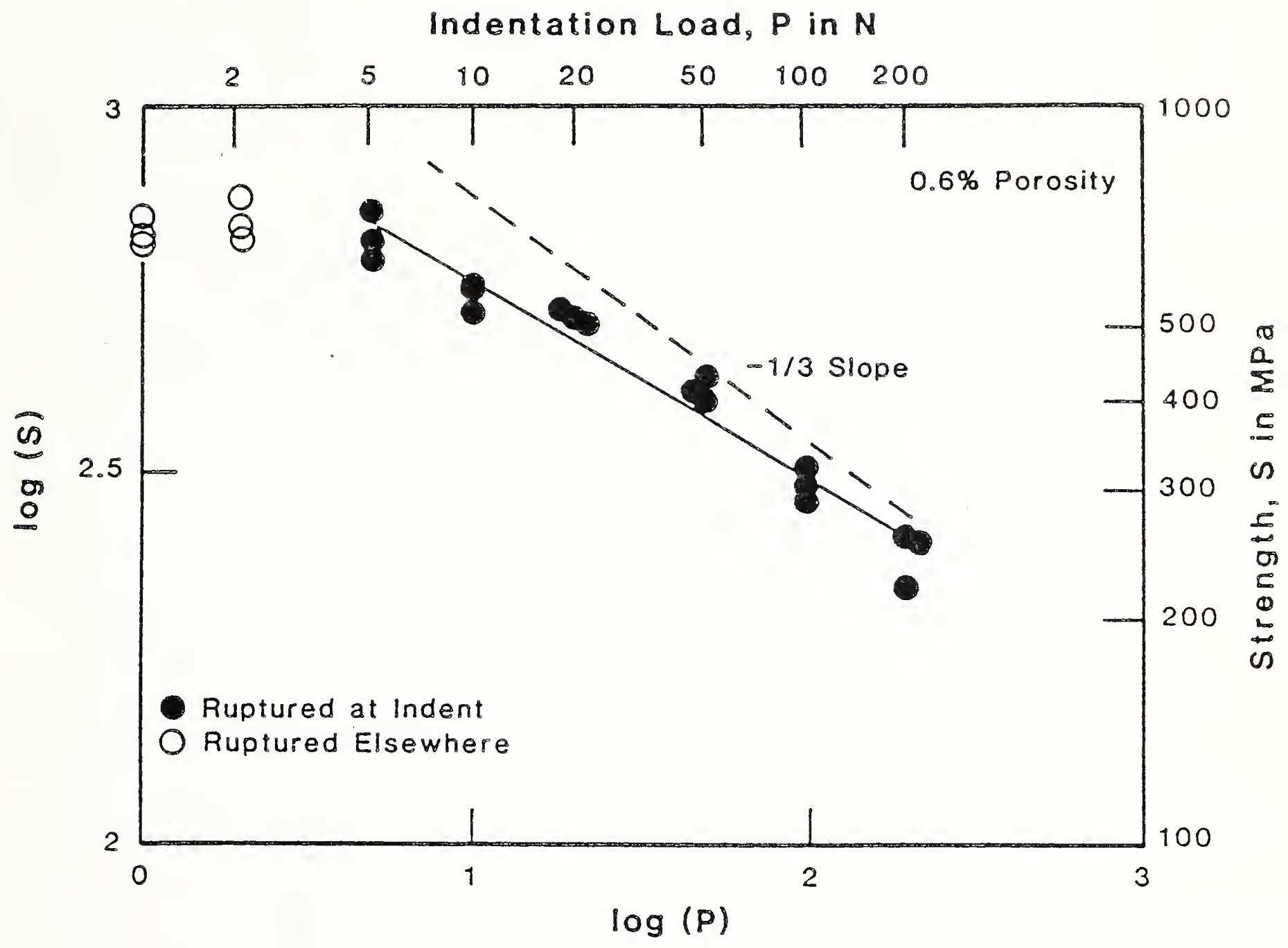

Figure 5. Flexural strength, $S$, as a function of indentation load, $P$, for a 25 wt percent silicon carbide whisker-reinforced alumina ceramic at 0.6 percent porosity. The solid line is a least-squares-fit for the solid points. 

Table 1. Values of parameters that define crack-extension in a 25 wt percent silicon carbide whisker-reinforced alumina ceramic at selected porosities. The uncertainty for each value is its standard deviation.

Parameter

Billet (a)

Billet (b)

Billet (c)

A. Porosity

P, percent

No. of measurements

B. Intrinsic Strength

$\mathrm{S}_{0}, \mathrm{MPa}$

No. of measurements

$$
421 \pm 11
$$

11
$11.48 \pm 0.16$

24

$$
4.89 \pm 0.14
$$

24

$$
\begin{array}{r}
559 \\
6
\end{array}
$$

$0.60 \pm 0.03$

24

$$
681 \pm 15
$$

C. Indented Beam Strength

$\beta$
$\mathrm{P}_{0}, \mathrm{~N}$
$\mathrm{No}$. of measurements

Percent $\left\langle\log _{e}(S)\right\rangle$

Student's $t$ for $95 \%$
$0.276 \pm 0.015$
$0.266 \pm 0.009$
$0.262 \pm 0.014$
8.5
$\pm 1.3$
$4.7 \pm 0.5$
$4.9 \pm 0.7$

13

18

$\pm 1.7$

$\pm 1.3$

18

$\pm 2.0$

confidence interval

1.80

1.75

1.75

D. Indented Crack Length

$c_{0}, \mu \mathrm{m}$

$28.9 \pm 2.4$

$18.1 \pm 1.2$

6

$\pm 1.5$

$\pm 1.3$

$18.8 \pm 1.6$

Percent $\log _{e}\left\langle c_{I}\right\rangle$

$0.068 \pm 0.018$

$0.080 \pm 0.012$

$0.084 \pm 0.018$

$\mathrm{K}_{0}, \mathrm{MPa} \cdot \mathrm{m}^{1 / 2}$

$5.17 \pm 0.25$

$5.35 \pm 0.17$

$6.61 \pm 0.32$

$c_{I} / c_{I}$

$2.66 \pm 0.04$

$2.69 \pm 0.03$

$2.70 \pm 0.04$ 

determined at each of the selected porosities. Only those indentation loads which correspond to the fractured surface having passed through a radial crack of an indentation flaw are considered valid points for the fit. The dashed line is a line of $-1 / 3$ slope, which a material with a fracture toughness that is invariant with crack size would indicate.

Fracture resistance. To facilitate analysis of the observed indentation-strength data, a parameric representation of the fracture resistance, $K_{R}$, as a fractional power function in crack extension, $\Delta c$, is used $[9,10]$, namely,

$$
\mathrm{K}_{\mathrm{R}}=\mathrm{K}_{\mathrm{o}}\left(\Delta \mathrm{c} / \mathrm{c}_{\mathrm{o}}\right)^{\mathrm{m}}
$$

where $\mathrm{K}_{0}, c_{0}$, and $\mathrm{m}$ are constants. The exponent m measures the susceptibility to R-curve behavior, that is, the susceptibility for fracture resistance to increase with crack extension. R-curve behavior arises because additional energy is required besides that needed at the crack tip to propagate the crack. The additional energy is required to overcome other energy consuming processes, such as tractions of aggregate interlock and/or pullout, or restraining forces of ligaments in the wake of the crack. In general, $\Delta c=c-c_{p}$, where $c$ is the total crack length and $c_{p}$ is a traction-free portion, such as exists in a prenotched specimen.

The lengths of surface cracks produced by indentation loading were measured by optical microscopy. Only values in the large crack region were used to evaluate the constant $c_{\circ}$ of Eq. (8). When indentation equilibrium is attained [10], the constant $c_{0}$ may be characterized by

$$
c_{0}=c_{I}\left(P_{0} / P\right)(1+\beta) / 2
$$

where $c_{I}$ is the half-length of surface crack. Figure 7 shows $c_{I}$ observed as a function of $P$. Notice the bias in the small crack region of indentation loads due to the failure to observe complete crack length by optical microscopy. Table 1 gives the mean value of $c_{0}$ determined at each of the selected porosities. 



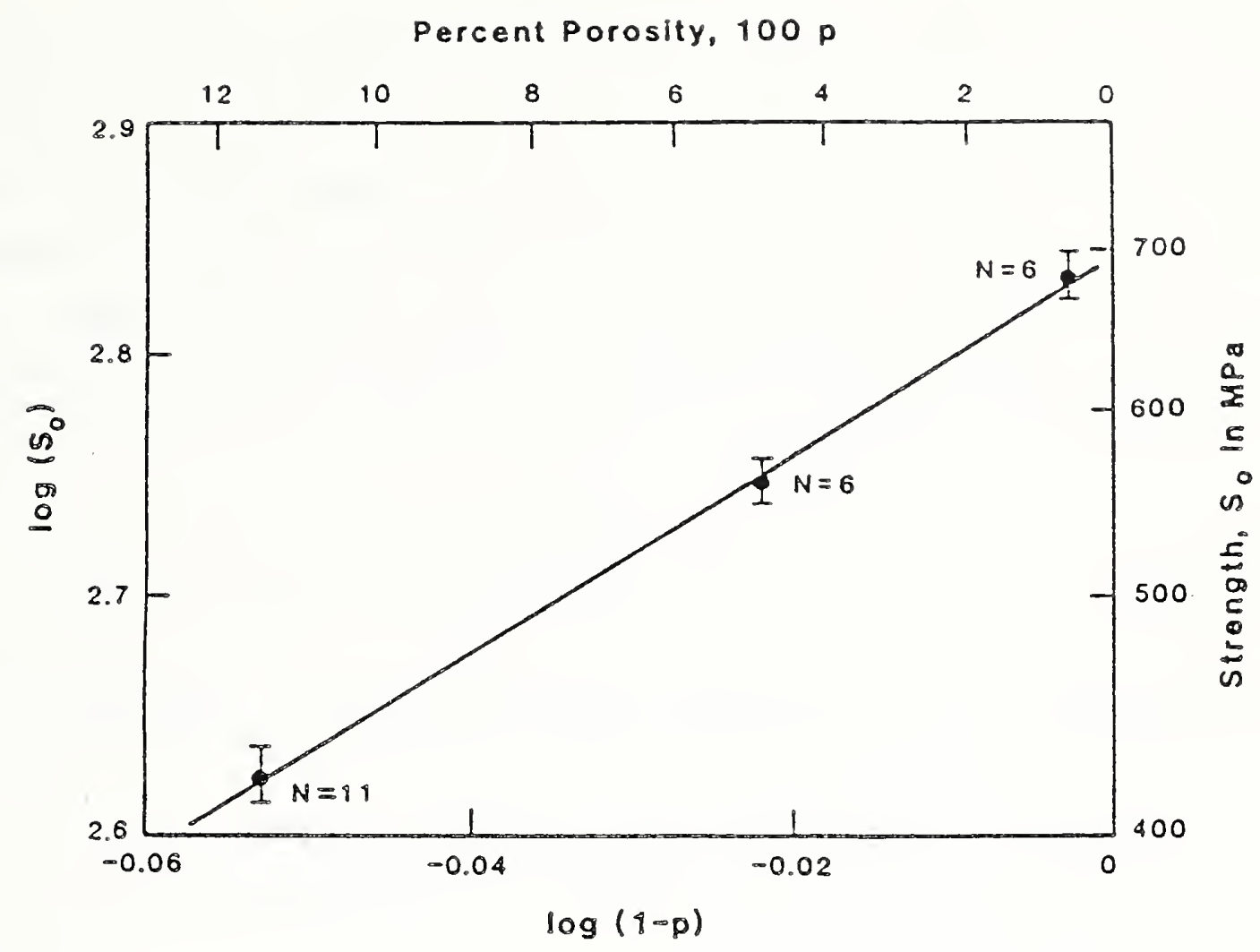

Figure 6. Intrinsic, flexural strength, $S_{0}$, as a function of porosity for a 25 wt percent silicon carbide whisker-reinforced alumina ceramic. The solid line is a least-squares-fit.

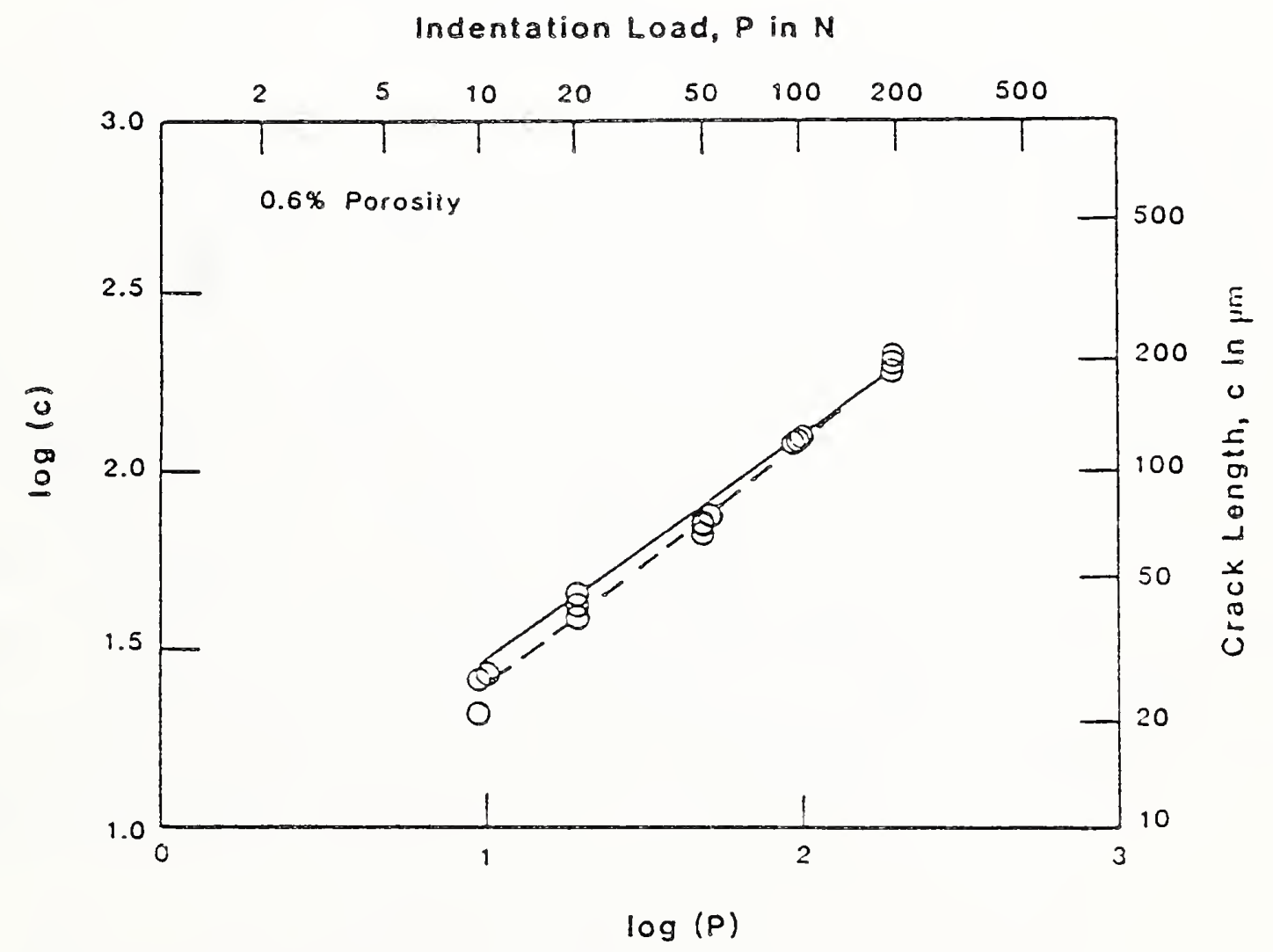

Eigure 7. Half-length of surface crack, $c=c_{I}$, as a function of indentatin load, $P$, for a 25 wt percent silicon carbide whiskerreinforced alumina ceramic at 0.6 percent porosity. The dashed line is a least-squares-fit, and the slope of the solid line is derived from the strength measurements. 

Solution of the fracture mechanics equations [10] enables an evaluation of the constants $K_{0}$ and $m$ of $E q .8$. The indentation flaw is considered to have extended to an onset of instability due to superposition of the stress-intensity factor for flexural loading on the residual stress intensity factor of indentation loading. The onset of crack-extension instability, $c_{I}$, is related to the indentation flaw size, $c_{I}$, by

$$
c_{I} / c_{I}=[4 /(1-2 m)]^{2 /(3+2 m)}
$$

When the solution is expressed in the form of Eq. (7), the constant $\beta$ is defined by

$$
\mathrm{m}=(1-3 \beta) /(2+2 \beta)
$$

and the constant $S_{0}$ is defined by

$$
K_{0}=Y S_{0} c_{0}^{1 / 2}(1+\beta)^{(1+\beta)} / \beta^{\beta}
$$

The reasonable fit of $\mathrm{Eq}$. (7) to the observed indentation-strength data does not invalidate the supposition of Eq. (8). Table 1 gives the values of $m$ and $K_{0}$ deduced from Eqs. (11) and (12), respectively, using $Y=$ 1.174 [9]. Figure 8 shows the fracture resistance, $K_{R}$, as a function of Eq. (8). The shaded region at each porosity in Fig. 8 describes the 95 percent confidence bands of the data and the range of experimental values of the critical stress-intensity factor, $K_{c}$, at the onset of crackextension instability, $c_{I}=\Delta c$. Decrease in the porosity of the composite raises the level of fracture resistance, but has negligible effect on the susceptibility for fracture resistance to increase with crack extension, which indicates that tractions in the wake of the crack are hardly affected by porosity. 



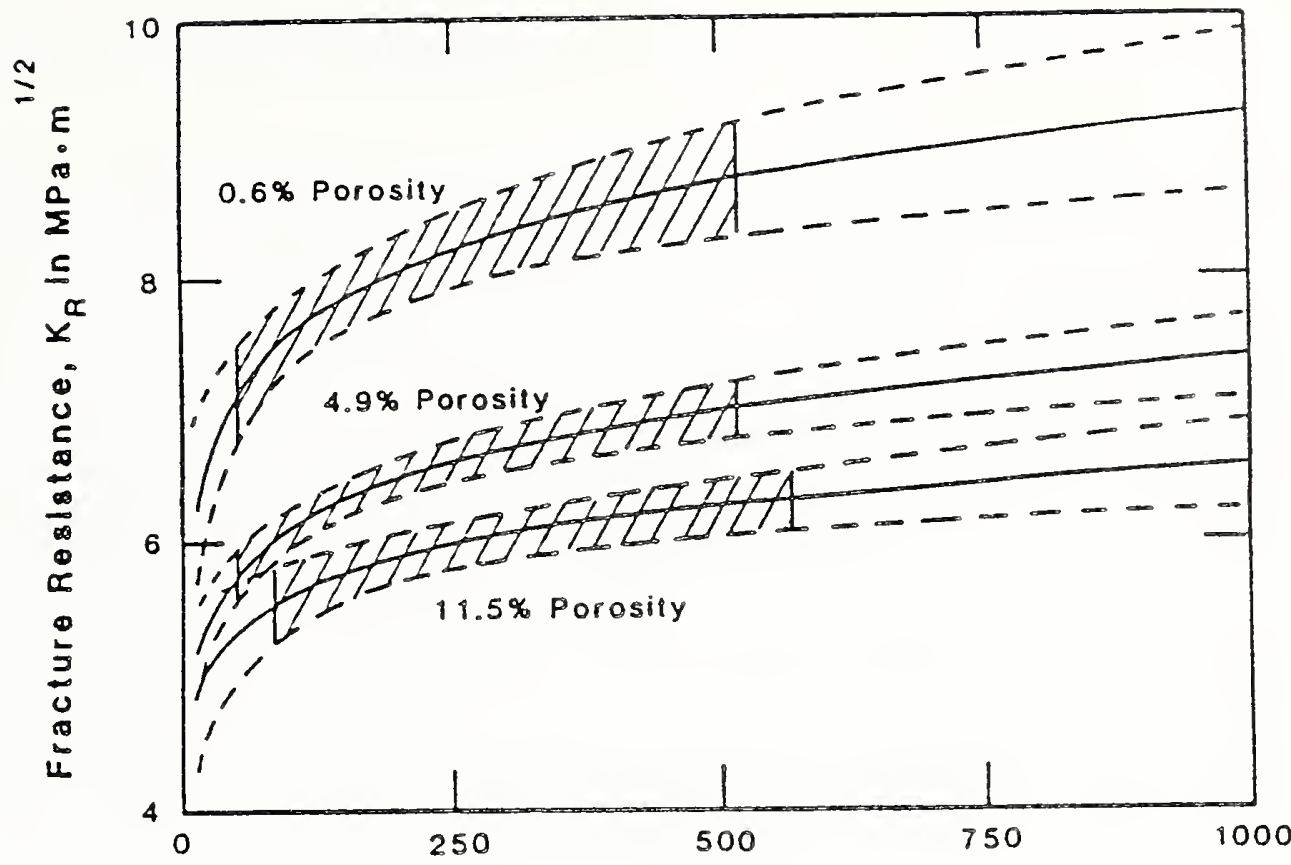

Crack Extension, $\Delta c$ in $\mu m$

Figure 8. Fracture resistance as a function of crack extension of a 25 wt percent silicon carbide whisker-reinforced alumina ceramic at selected porosities. The shaded regions denote the range for the onset of crackextension instabilities deduced in the experiments, and the dashed lines describe the 95 percent confidence intervals of $K_{R}$.

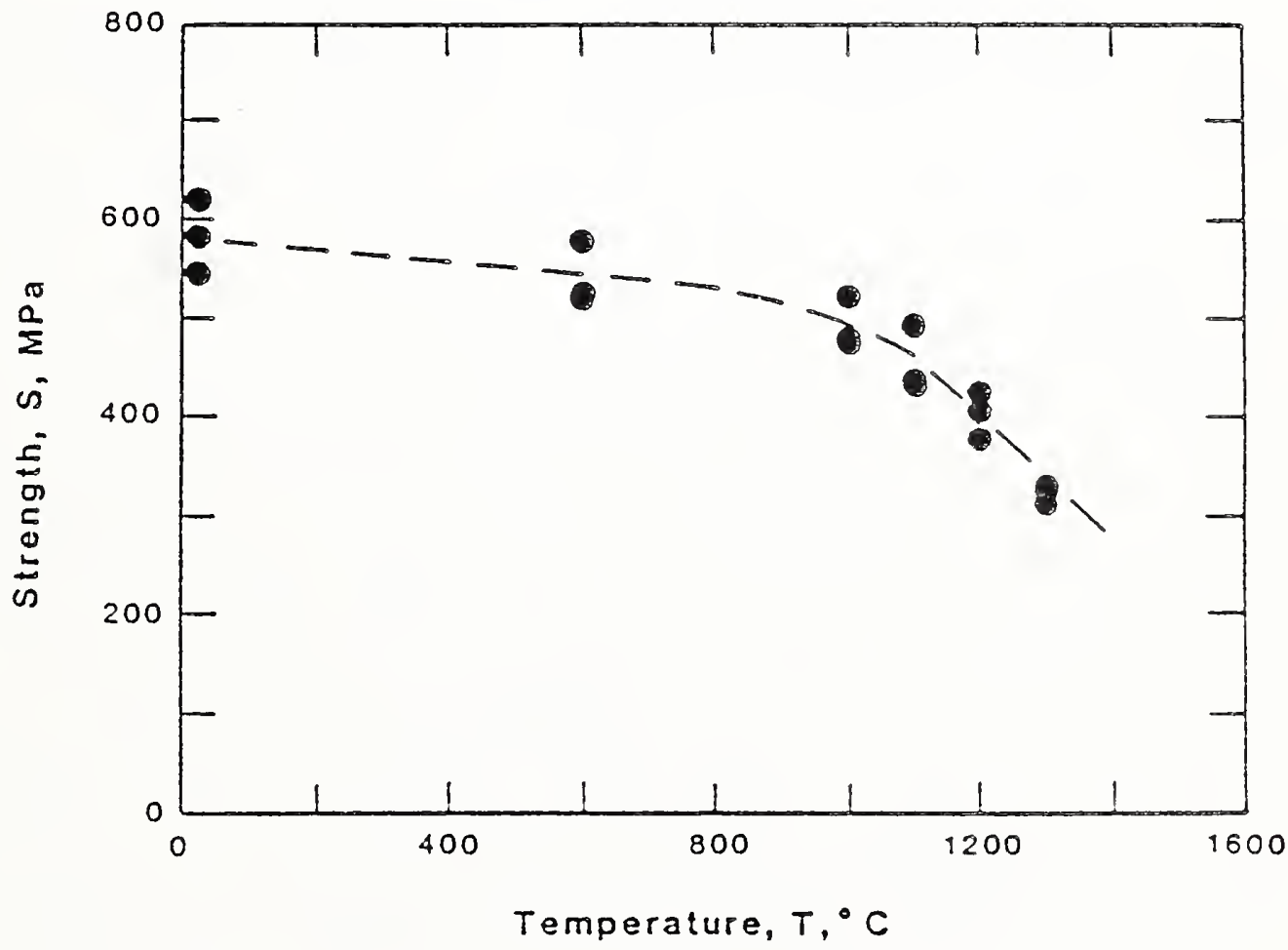

Figure 9. Flexural strength versus temperature for a 25 wt percent silicon carbide whisker-reinforced alumina ceramic of 4.9 percent porosity. 

Summary. The intrinsic strength of a 25 wt percent silicon carbide whisker-reinforced alumina ceramic with 4.9 percent porosity was determined by rapid loading of four-point flexure specimens at several temperatures between 25 and $1300^{\circ} \mathrm{C}$. While the strength remained approximately invariant up to $900^{\circ} \mathrm{C}$, it regressed above this temperature, becoming almost half as strong at $1300^{\circ} \mathrm{C}$.

The creep strain and creep rupture of this material was measured in four-point flexure as a function of flexural stress (corresponding to applied stresses between 98 and $374 \mathrm{MPa}$ ) and temperature (from 1000 to $1300^{\circ} \mathrm{C}$ ). At $1000^{\circ} \mathrm{C}$ a specimen displayed approximately 0.2 percent strain without rupture, following a period of $1230 \mathrm{~h}$, during which it was under a stress of $300 \mathrm{MPa}$. At $1120^{\circ} \mathrm{C}$ another specimen displayed approximately 0.5 percent strain without rupture, following a period of $1590 \mathrm{~h}$, during which it was under a stress of $149 \mathrm{MPa}$. Creep strain to failure ranged between 0.1 and 1.6 percent, decreasing with increasing stress at a given temperature and increasing with increasing temperature at a given stress. The time required to rupture a specimen ranged from 0.3 to $865 \mathrm{~h}$.

High-temperature strength. Flexure specimens, $3 \mathrm{~mm} \times 4 \mathrm{~mm} \times 50 \mathrm{~mm}$, were cut and ground the same as those used in the fracture toughness study [1] except these did not receive the $9 \mu \mathrm{m}$ finishing polish. Using nitrocellulose cement, they were mounted in place on silicon carbide platens with fixed $3 \mathrm{~mm}$ diam loading bars. Constant loading on a specimen was applied through a pneumatic cylinder with a lubricated rubber diaphragm. A controlled-leak, pressure regulator was capable of maintaining the applied load within $\pm 2 \mathrm{~N}$. The load was transmitted through $19 \mathrm{~mm}$ diam rods of 99 percent recrystallized silicon carbide, bearing on a hemi-spherical compression tool of the same material. Three sets of loading rods protruded through the roof and floor of an aluminainsulated furnace cavity, $150 \mathrm{~mm}$ x $200 \mathrm{~mm} \times 150 \mathrm{~mm}$ high, to accomodate three test specimens simultaneously. Two such furnace assemblies were used in these tests. A pre-load of approximately $10 \mathrm{~N}$ maintained the allignment of a specimen while it was heated to the test temperature, during which the nitrocellulose cement burned away. The furnace cavity 

was heated to the test temperature in approximately one hour by molybdenum disilicide heating elements, radiating from the side walls within the furnace cavity. The temperature was controlled and measured by calibrated platinum-rhodium thermocouples. The loading rods were water-cooled where they were connected to air cylinders and load transducers, which were supported in the same Erame above and below the furnace, respectively. The load transducers were calibrated with known weights and were read through a chart recorder. After the specimens were held at an elevated temperature for approximately one hour, the loads were increased at a uniformly rapid rate to rupture the specimens in succession by increasing the pressure in the air cylinders. Rubber shock absorbers prevented an interaction amongst the loading rams.

The flexural strength, $S$, was characterized by

$$
S=3 F\left(\ell_{1}-\ell_{2}\right) / 2 b w^{2}
$$

where $F$ is the rupture load; $\ell_{1}=40 \mathrm{~mm}$ and $\ell_{2}=10 \mathrm{~mm}$ are the outer and inner loading spans, respectively; and $b=4 \mathrm{~mm}$ and $\dot{w}=3 \mathrm{~mm}$ are the nominal dimensions of a specimen. Figure 9 shows the results of the strength tests as a function of temperature.

Creep strain and rupture time. The same procedure described above for the high-temperature strength tests were used to conduct creep experiments except that only two specimens were placed in a furnace cavity and the stress applied at the elevated temperature was something less than approximately half the material strength. Also, the loadingpoint displacement, $y$, was measured as a function of time, $t$. The creep strain, $\epsilon$, was characterized by [11]

$$
\epsilon=6 \mathrm{yw} /\left(\ell_{1}^{2}+\ell_{1} \ell_{2}-2 \ell_{2}^{2}\right)
$$

for which the neutral axis of bending was assumed to be at the geometric center of the specimen and the stress exponent was assumed as linity.

The loading-point displacement during creep was monitored by a linear voltage displacement transducer that was attached to each watercooled holder of an upper ram of the test equipment. The transcucers 

were calibrated with known gauge blocks, and the displacement was measured within $\pm 5 \mu \mathrm{m}$. To enhance the long-term accuracy of the displacement readings, a block of silicon carbide, the same as that used for the rams, was used in the middle test station of a furnace. Any displacement measured on the block is believed to reflect changes in the test facility due mainly to fluctuations in the ambient temperature. These displacement fluctuations were substracted from the displacements measured on the specimens in the other two stations of the same furnace so that errors due to differential thermal expansion of the test facility were minimized. The failure of one specimen in a furnace was observed to have negligible effect on the other specimen, mainly because the pneumatic piscons and rubber shock absorbers were used to restrain the propagation of stress-waves.

Two examples of typical curves of creep strain versus time are shown in Fig. 10. They exhibit a work-hardening of the material right up to the time of rupture. Table 2 gives a summary of the experiments conducted to date. Strain valves with a greater-than-symbol refer to specimens that had not as yet ruptured up to the time indicated. Creep strain was hardly perceptible at $1000^{\circ} \mathrm{C}$, but the considerable creep strain at $1300^{\circ} \mathrm{C}$ indicates a specimen to specimen variation by at least a factor of two. The apparent work-hardening characteristic of creep strain was represented by

$$
\epsilon=B t^{\mathrm{a}}
$$

where $a$ and $B$ are constants. Least-squares fits of the logarithm of Eq. (15) are shown in Fig. 11. The time exponent, a, appears to remain fairly uniform over the range of stresses shown at a given temperature.

Future creep studies. The apparent work-hardening characteristic of creep strain may be in part a manifestation of a shift in the neutral axis. We plan to examine this phenomena by comparing strains calculated from loading point displacement with those calculated from the radius of curvature. Also, an examination of the distribution of strain along the specimen height would indicate any possible shift in the neutral axis. The observed creep strain data will be analysed to relate strain rate as 



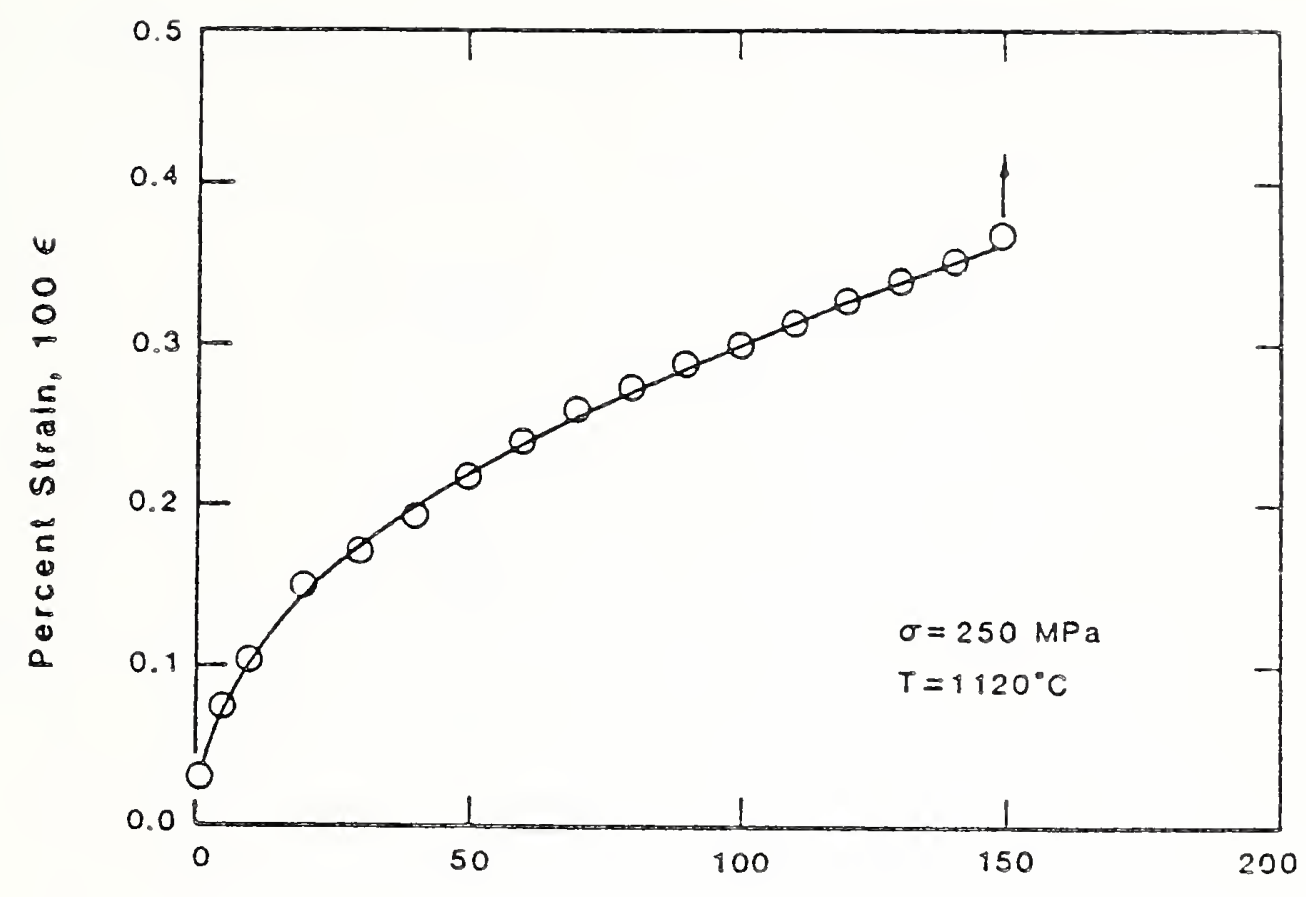

Time, $t$, hour

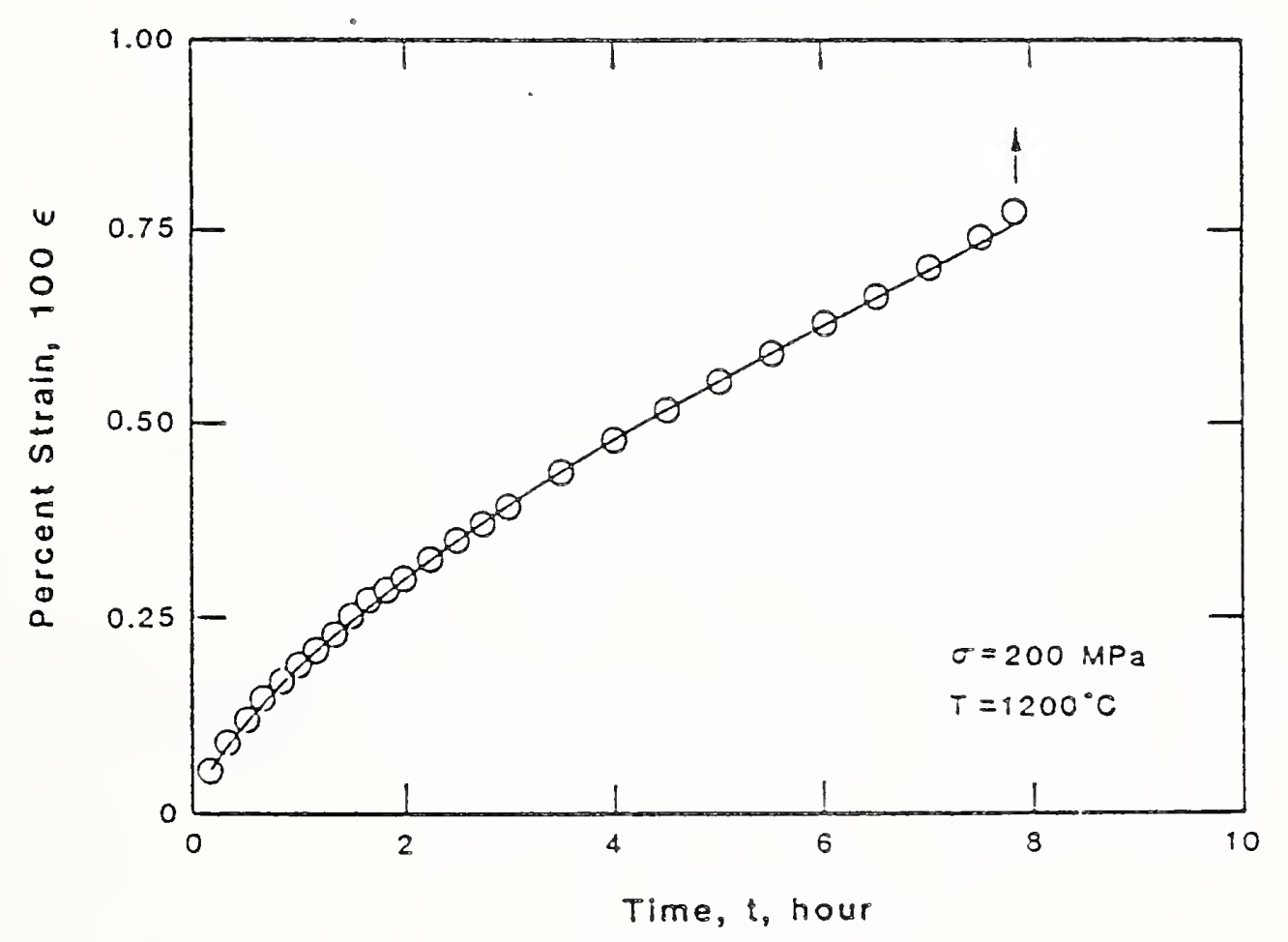

Figure 10. Typical curves of creep strain versus time for flexure specimens of a 25 wt percent silicon carbide whisker-reinforced alumina ceramic of 4.9 percent porosity under the given appiied stress at selected temperatures. The solid lines are least-squares fits. 

Table 2. Creep rupture behavior of a 25 wt percent silicon carbide whiskerreinforced alumina ceramic, having 4.9 wt percent porosity.

Temperature

${ }^{\circ} \mathrm{C}$
Applied Stress

$\mathrm{MPa}$
Percent Strain

at Failure
Failure Time

h

\begin{tabular}{|c|c|c|c|}
\hline \multirow{4}{*}{1000} & $\begin{array}{l}202^{a} \\
301\end{array}$ & $\begin{array}{l}>0.04 \\
>0.23\end{array}$ & $\begin{array}{l}>360 \\
>1230\end{array}$ \\
\hline & & & \\
\hline & $249^{\circ}$ & $>0.04$ & $>360$ \\
\hline & 374 & 0.01 & 87 \\
\hline \multirow{5}{*}{1120} & 126 & $>0.32$ & $>1590$ \\
\hline & 149 & $>0.52$ & $>1590$ \\
\hline & & & \\
\hline & 200 & 0.53 & 865 \\
\hline & 250 & 0.36 & 149 \\
\hline \multirow{4}{*}{1200} & 124 & $>0.45$ & $>290$ \\
\hline & 149 & 1.04 & 61 \\
\hline & 200 & 0.73 & 7.5 \\
\hline & 249 & 0.15 & 0.3 \\
\hline & 98 & 1.61 & 14 \\
\hline 1300 & 124 & 0.87 & 16 \\
\hline
\end{tabular}

aThis is the preliminary stress on a specimen. Following a period of $360 \mathrm{~h}$ the load on the same specimen was increased to that shown on the subsequent line. 

Time, t, hour

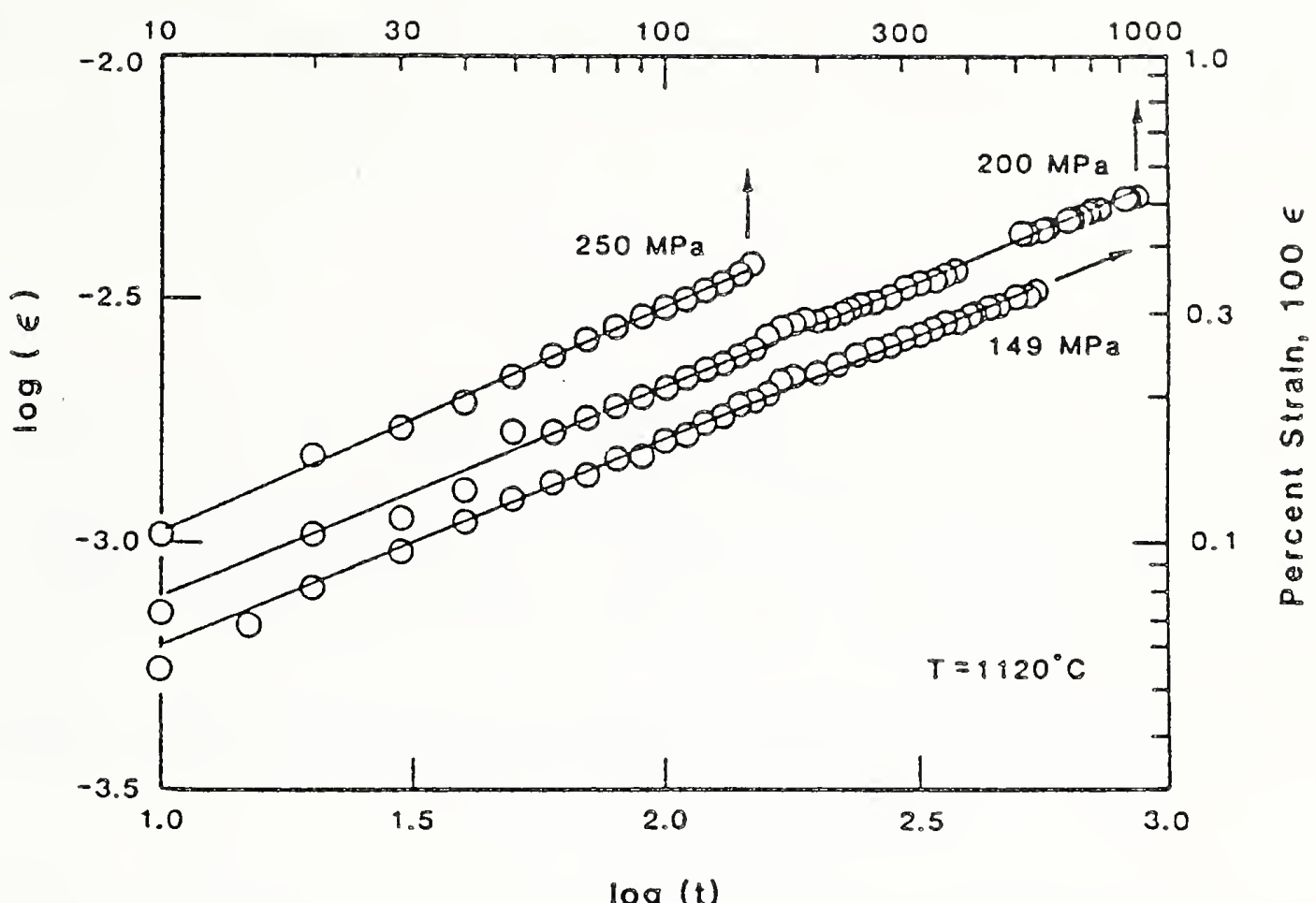

Time, $t$, hour

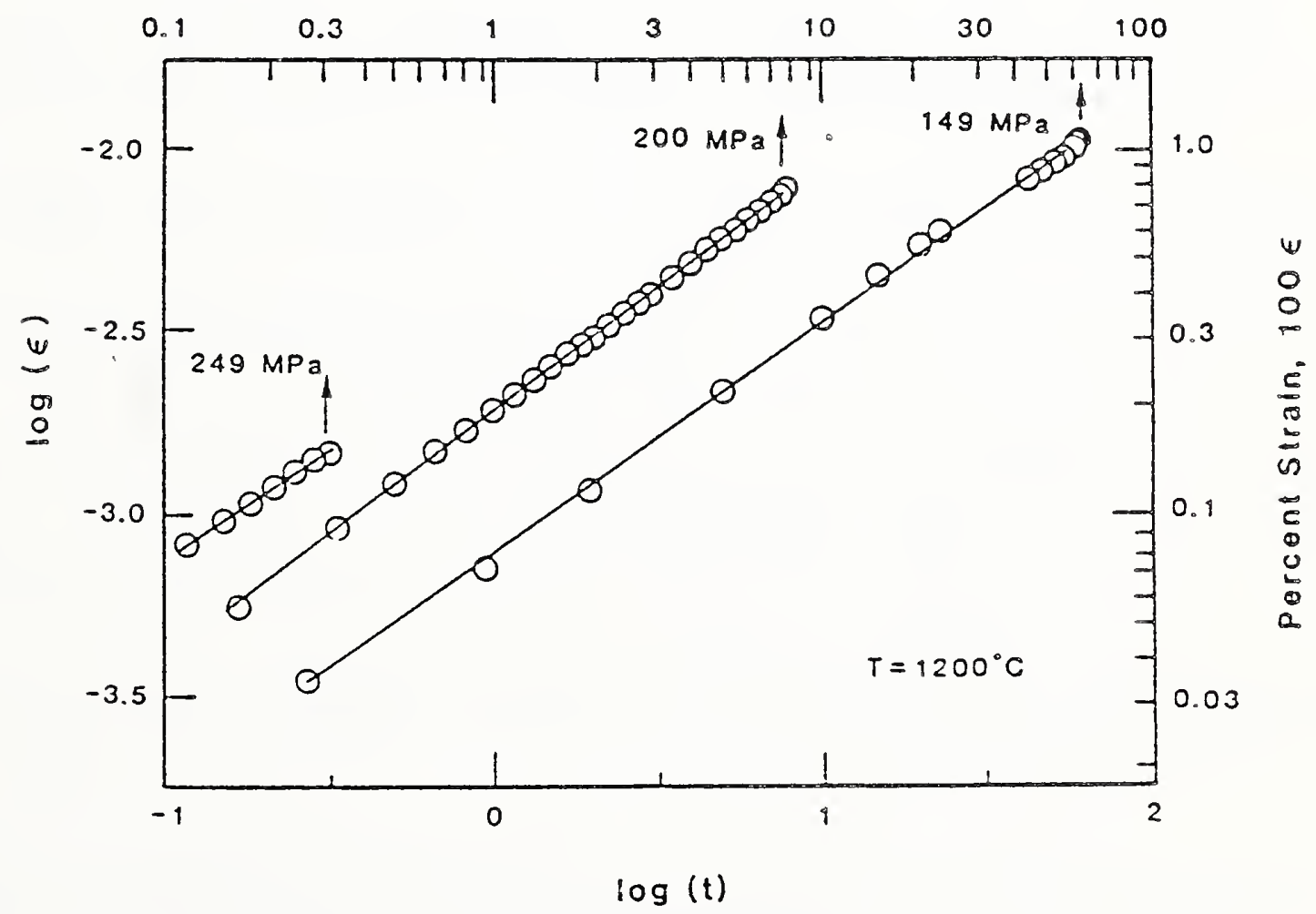

Figure 11. Straight line, least-squares fits of the logarithm of Eq. (15), showing creep strain versus time for fiexure specimens of a 25 wt percent silicon carbide whisker-reinforced alumina ceramic of 4.9 percent porosity under given applied stresses of constant loading at selected temperatures. 

functions of applied stress, temperature, and time to failure. Determination of the fracture resistance at elevated temperatures would indicate the extent of crack-extension to be expected up to the time of failure for a specimen under a given stress.

\section{REFERENCES}

1. E.R. Fuller, Jr., T.W. Coyle, R.F. Krause, Jr., and T.J. Chuang, "Structural Reliability and Damage Tolerance of Ceramic Composites for High-Temperature Applications," Semiannual Progress Report ORNL/FMP$87 / 1$, Fossil Energy Materials Program, R.R. Judkins, Manager, Oak Ridge National Laboratory, Oak Ridge, TN, July 1987, pp. 115-140.

2. C. Janssen, "Specimen for Fracture Mechanics Studies on Glass", Proceedings of the Xth International Congress on Glass, Kyoto, Japan, The Ceramic Society of Japan, 1974, pp. 23-30.

3. H. Richter, "Crack Propagation in Glass Under Liquids in an Intermediate Range of Crack Velocities", Strength of Inorganic Glass, ed. C.R. Kurkjian, Plenum Publishing Corp., NY, 1985, pp. 219-229.

4. J.H. Henry, "Energie d'Avancement de Fissure, G, pour une Plaque Percee d'un Trou Soumise en Compression', Mechanics Research Communications 10 (5) 253-257 (1983).

5. C.G. Sammis and M.F. Ashby, "The Failure of Brittle Porous Solids Under Compressive Stress States", Act Metal1. 34 511-526 (1986).

6. W.E. Warren, "Theoretical Analysis of the Double Cleavage Drilled Compression Specimen", Int. Journal of Fract. 33 223-325 (1987).

7. H. Tada, P.C. Paris, and G.R. Irwin, The stress analysis of Cracks Handbook, Del Research Corp., Hellertown, PA, 1973.

8. J.F. Rhodes, ARCO Chemical Company, Greer, SC, May 14, 1986.

9. R.F. Krause, Jr., "Rising Fracture Toughness from the Bending Strength of Indented Alumina Beams," submitted to the J.Amer. Ceram. Soc., August 1986.

10. R.F. Krause, Jr. and E.R. Fuller, Jr., "Fracture Toughness Behavior of a Silicon Carbide Whisker-Reinforced Alumina Ceramic at Selected Porosities," in Fossil Energy Materials Program Conference Proceedings, ed. by R.R. Judkins, Oak Ridge National Laboratory, Oak Ridge, TN, Aug. 1987, PP. 38-55.

11. G.W. Hollenberg, G.R. Terwilliger, and R.S. Gordon, "Calculation of Stresses and Strains in Four-Point Bending Creep Tests," J. Amer. Ceram. Soc. 54 196-199 (1971). 

4. TITLE AND SUBTITLE

STRUCTURAL RELIABILITY AND DAMAGE TOLERANCE OF CERAMIC COMPOSITES FOR HIGHTEMPERATURE APPLICATIONS

Semi-Annual Progress Report for the Period Ending September 30, 1987.

5. $\operatorname{AUTHOR}(S)$

E. R. Fuller, Jr., T.W. Coyle, and R. F. Krause, Jr.

6. PERFORMING ORGANIZATION (If joint of other than NBS, see insiructions)

7. Contracd Grane No.

\section{NATIONAL BUREAU OF STANDARDS \\ U.S. DEPARTMENT OF COMMERCE GAITHERSBURG, MD 20899}

\section{SPONSORING ORGANIZATION NAME AND COMPLETE ADDRESS (Street, City, Stote, ZIP)}

US Dept. of Energy, Fossil Energy

Advanced Res. \& Technology Development

Fossil Energy Materials Program

Oak Ridge National Lab., Oak Ridge, TN

10. SUPPLEMENTARY NOTES

Document describes a computer program; SF.185, FIPS Software Summary, is attached.

11. ABSTRACT (A 200-word or less foctual summory of most significant information. If document includes a significane bibliogrophy or literature survey. mention it here)

The achievement of higher efficiency heat engines and heat recovery systems requires the availability of high-temeprature, high-performance structural materials. Structura ceramics, and more recently, ceramic matrix composites have received particular attention for these applications due to their high strength, and resistance to corrosion and thermal shock. Even with these positive attributes, improved reliability and extended lifetime under service conditions are necessary for structural ceramics to gain industrial acceptance. The problems with these materials are mechanical and chemical in nature and are enhanced by the fact that they are subjected to high temperatures, reactive environments and extreme thermal gradients.

With an objective of improved performance for heat engine/heat recovery applications, the NBS program on structural ceramics and ceramic composites addresses these problems through the determination of critical factors that influence mechanical and microstructural behavior. The activites of the program are grouped under two major subtasks, each designed to develop key data, associated test methods and companion predictive models. The status of the subtasks are detailed in the following sections.

12. KEY WORDS (Six to twelve entries; alphabetical order: capitalize only proper names; and separate key words by semicolons) composites; double-cleavage-drilled-compression; indentation; R-curve; SiC fibers; SiC whiskers; shear resistance; strength

13. AVAILABILITY

$X$ Unlimited

For Official Distribution. Do Not Release to NTIS

Order From Superintendent of Documents, U.S. Government Printing Office, Washington, D.C. 20402.

X Order From National Technical Information Service (NTIS), Springfield, VA. 2216।
14. NO. OF

PRINTED PAGES

26

15. Price

$\$ 11.95$ 


